\title{
Toluene Permeation through Solid Polymer Electrolyte during Toluene Direct Electro-hydrogenation for Energy Carrier Synthesis
}

\author{
Kensaku Nagasawa ${ }^{a}$, Keisuke Tanimoto ${ }^{b}$, Junpei Koike ${ }^{b}$, Kaoru Ikegami ${ }^{b}$ and Shigenori \\ Mitsushima $^{\text {a,b }}$ \\ anstitute of Advanced Sciences, Yokohama National University, 79-5 Tokiwadai, Hodogaya-ku, \\ Yokohama 240-8501, Japan \\ ${ }^{\mathrm{b}}$ Green Hydrogen Research Center, Yokohama National University, 79-5 Tokiwadai, Hodogaya-ku, \\ Yokohama 240-8501, Japan
}

Corresponding author: Kensaku Nagasawa, Tel: +81-45-339-3872, Fax: +81-45-339-4024.

E-mail: nagasawa-kensaku-st@ynu.ac.jp

\begin{abstract}
For the transportation and storage of hydrogen energy by toluene-methylcyclohexane organic hydride systems, the performance of toluene direct electro-hydrogenation electrolyzers using solid polymer electrolytes (SPE) for the membrane and ionomers must be improved. In this study, we investigate the effect of the equivalent weight $(E W)$ and the side-chain length of the SPE on toluene permeability and electrochemical performance. The SPE membrane with a lower $E W$ and a shorter side chain shows a lower toluene permeability. The lower $E W$, with higher acidity, decreases toluene solubility by saltingout in the hydrophilic mass transport path. The shorter side chain, which lowers the water uptake, suppresses toluene permeation by decreasing the cross-sectional area of the mass transport path. In the electrochemical measurement using the electrolyzer, the combination of SPEs with long side chain and high $E W$ for both the membrane and ionomer shows the best performance. For long-term anode deactivation by membrane-permeated toluene, the membrane should be designed to reduce toluene permeability. Meanwhile, the ionomer has the advantage of higher $E W$ and long side chain.
\end{abstract}

Keywords: organic hydride; toluene; solid polymer electrolyte; permeability; electro-hydrogenation

\section{Introduction}

Renewable energy sources, such as wind, solar and geothermal power, are increasingly being used to combat global warming and the depletion of fossil fuels. However, the region-specific distribution and unstable supply of renewable energy sources present problems in their large-scale utilization. Thus, 
the conversion of renewable energy to chemical energy, such as hydrogen, is essential for energy storage and transportation [1].

Toluene-methylcyclohexane [2,3], liquid hydrogen, and ammonia have been identified as potential candidates to be the hydrogen energy carrier [4]. The toluene-methylcyclohexane organic hydride system has the strong advantage of long-distance transportation with the cycle containing hydrogenation and dehydrogenation [5]. This is because both toluene and methylcyclohexane have low vapor pressure and can be easily handled as they are in the liquid phase at ambient temperature and pressure, and the required infrastructure is already available in petroleum industries. Hence, on a global scale, this system is suitable for hydrogen transportation from the endowment area of renewable energy to the consumption area of the hydrogen energy by marine transport [4]. On the other hand, other than toluene, hydride combinations with benzene [6], xylene [7] or naphthalene [8], etc. have been considered for the organic chemical hydride systems [9]. Among these aromatic compounds, toluene has the advantage of low toxicity and high stability [10].

In the conventional process, toluene hydrogenation involves a two-step reaction, consisting of water electrolysis and subsequent toluene hydrogenation using the formerly-produced hydrogen, as follows:

$$
\begin{array}{ll}
2 \mathrm{H}_{2} \mathrm{O}(\mathrm{l}) \rightleftharpoons \mathrm{O}_{2}(\mathrm{~g})+4 \mathrm{H}^{+}(\mathrm{aq})+4 \mathrm{e}^{-} & \text {(1st step, anode) } \\
2 \mathrm{H}^{+}(\mathrm{aq})+2 \mathrm{e}^{-} \rightleftharpoons \mathrm{H}_{2}(\mathrm{~g}) & \text { (1st step, cathode) } \\
\mathrm{C}_{6} \mathrm{H}_{5} \mathrm{CH}_{3}(\mathrm{l})+3 \mathrm{H}_{2}(\mathrm{~g}) \rightarrow \mathrm{C}_{6} \mathrm{H}_{11} \mathrm{CH}_{3}(\mathrm{l}) & \text { (2nd step) }
\end{array}
$$

Herein we studied the process of toluene direct electro-hydrogenation [11, 12], where toluene hydrogenation and water decomposition occur simultaneously at the cathode and anode, respectively, through a proton exchange membrane (PEM). This electrocatalytic one-step reaction proceeds as follows:

$$
\begin{array}{ll}
2 \mathrm{H}_{2} \mathrm{O}(\mathrm{l}) \rightleftharpoons \mathrm{O}_{2}(\mathrm{~g})+4 \mathrm{H}^{+}+4 \mathrm{e}^{-} & \text {(anode) } \\
\mathrm{C}_{6} \mathrm{H}_{5} \mathrm{CH}_{3}(\mathrm{l})+6 \mathrm{H}^{+}+6 \mathrm{e}^{-} \rightleftharpoons \mathrm{C}_{6} \mathrm{H}_{11} \mathrm{CH}_{3}(\mathrm{l}) & \text { (cathode) }
\end{array}
$$

It has the following advantages: there is no exothermic heat loss due to the absence of the hydrogen evolution reaction, and the theoretical decomposition voltage can be reduced from 1.23 to $1.08 \mathrm{~V}$. The electro-hydrogenation reaction at the cathode is very fast and it is thus an efficient system [12, 13]. In this electrolyzer, the oxygen evolution reaction (OER) occurs at a DSA ${ }^{\circledR}$-type anode. The small amount of toluene that escapes from the cathode to the anode side through the PEM during long-term operation decreases the anode activity and durability [14]. Therefore, the suppression of toluene permeation through the PEM is required to maintain a high electrolysis efficiency. 
Nafion ${ }^{\circledR}$ is widely used as PEMs and ionomers for polymer electrolyte fuel cells (PEFCs) and proton exchange membrane water electrolyzers (PEMWEs). It has high proton conductivity and high chemical, mechanical and thermal stabilities. Aquivion ${ }^{\circledR}$ membranes and ionomers have a higher thermal stability than Nafion ${ }^{\circledR}$ due to their higher glass transition temperature in the dry state. In addition, Aquivion ${ }^{\circledR}$ has a lower equivalent weight $(E W)$ and shorter side chain structure than Nafion ${ }^{\circledR}$ $[15,16]$. Figure 1 shows the polymer structures of $\mathrm{Nafion}^{\circledR}$ and Aquivion ${ }^{\circledR}$. Nafion ${ }^{\circledR}$ and Aquivion ${ }^{\circledR}$ have long-side-chain (LSC) and short-side-chain (SSC) type structures, respectively $[17,18]$. In toluene direct electro-hydrogenation, toluene permeability of the PEM is an important property as already mentioned. However, to the best of our knowledge, the effect of $E W$ and polymer structure of solid polymer electrolytes (SPE) on toluene permeation have not yet been investigated. On the other hand, in toluene direct electro-hydrogenation electrolyzer, the different EW and polymer structures of the SPE containing PEM and ionomers would affect the electrochemical performance. We have previously reported on the enhancement of the electrochemical performance by improvement of the anode [14] and cathode [19, 20] catalysts, flow field [21], and diffusion layer [22]. However, studies on the SPE have not been reported.

In this study, we investigated the effect of $E W$ and side-chain length of the PEM on toluene permeability using a two-chamber cell. Furthermore, the electrochemical performance of the toluene direct electro-hydrogenation electrolyzer was determined for the PEMs and ionomers with different EW and polymer structures.

\section{Experimental}

The PEMs used for the toluene permeation tests were Nafion ${ }^{\circledR} 117$ (DuPont), Nafion ${ }^{\circledR}$ NRE212 (DuPont), Aquivion ${ }^{\circledR}$ E87-05S (Solvay), and Aquivion ${ }^{\circledR}$ E98-05S (Solvay). The thickness, EW, and polymer structure of each membrane are shown in Table 1. The permeation tests were conducted using a two-chamber cell as shown in Fig. 2(a), which was separated by a PEM with an effective permeation area of $12.6 \mathrm{~cm}^{2}$. A $120 \mathrm{~mL}$ aliquot of toluene (Aldrich, anhydrous, $\left.99.8 \%\right)$ and $1 \mathrm{M} \mathrm{(=} \mathrm{mol} \mathrm{dm}$ sulfuric acid (Wako Pure Chemical Industries, Ltd., 95+\% (Ti) H. S.) was added to each chamber. The cell was placed in a water bath to maintain a temperature range from 25 to $70{ }^{\circ} \mathrm{C}$. To determine the permeated-toluene concentration, sulfuric acid was sampled from the chamber, and added to $\mathrm{N}, \mathrm{N}-$ dimethylformamide (DMF, Wako Pure Chemical Industries, Ltd., 99.7+\% (cGC), for HPLC) to stabilize the dissolved toluene, because DMF has a high affinity for both toluene and sulfuric acid. The toluene concentrations in the DMF-mixed samples were determined by high-performance liquid chromatography (HPLC, Shimadzu, Prominence UFLC).

Figure 2(b) shows a schematic image of toluene solubility measurement in sulfonic acid. Thirty $\mathrm{mL}$ samples of toluene and $1 \mathrm{M}$ sulfuric acid were placed in a separating funnel and held in a thermostat 
chamber for a temperature range from 30 to $70{ }^{\circ} \mathrm{C}$. Toluene solubility was determined as the saturation concentration after a specific time.

The HPLC was operated under the following conditions for the permeation test and solubility measurement: The column (VP-ODS, Shimadzu) temperature was $40{ }^{\circ} \mathrm{C}$. The mobile phase was a solution of methanol (Wako Pure Chemical Industries, Ltd., 99.7+\% (cGC), for HPLC) and distilled water (Wako Pure Chemical Industries, Ltd., for HPLC) (methanol: distilled water $=7: 3$ ). The flow

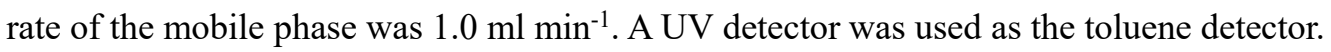

The electrochemical measurements using the SPE membrane and ionomer were performed using the toluene direct electro-hydrogenation electrolyzer as shown in Fig. 2(c). The electrode area was 3.5 $\times 3.3 \mathrm{~cm}^{2}$, and the clamping pressure of the membrane cathode assembly (MCA) and the anode, obtained using a busbar and spring, was $3 \mathrm{kgf} \mathrm{cm}^{-2}$. The membrane and ionomer of the MCAs involved 4 types of combinations of the NRE212 and E87-05S membranes, and Nafion and Aquivion ionomers. The anode used the Ir oxide-based DSE ${ }^{\circledR}$ electrode for oxygen evolution (De Nora Permelec, Ltd.). The MCA was fabricated by the following method: The cathode catalyst ink was made by mixing 1propanol, distilled water, PtRu/C (TEC61E54, Tanaka Kikinzoku Kogyo) and a perfluoro-sulfonic acid (PFSA) polymer dispersion of 5\% Nafion ${ }^{\circledR}$ (DuPont) or $6 \%$ Aquivion $^{\circledR}$ (Solvay) solution by ballmilling for $10 \mathrm{~min}$ at $200 \mathrm{rpm}$ in a $100-\mathrm{mL}$ pod. The weight ratio of the PFSA polymer to carbon was 0.8: 1.0. The mixed ink was applied on the carbon paper (10BC, SGL Carbon, Ltd.) by a bar-coater at a $0.5 \mathrm{mg}$-PtRu $\mathrm{cm}^{-2}$ loading. The carbon paper was loaded with $0.02 \mathrm{mg} \mathrm{cm}^{-2}$ of Pt nanoparticles as the toluene chemical-hydrogenation catalyst, before applying the catalyst ink [22]. The Pt loading was conducted by the impregnation method, where the $\mathrm{Pt}$ ion was reduced in the $\mathrm{H}_{2} \mathrm{PtCl}_{6}$ solution using $\mathrm{NaBH}_{4}$. The average Pt loading amount in the carbon paper was measured by the change in weight of the carbon paper before and after the loading. The value was $0.020 \pm 0.005 \mathrm{mg} \mathrm{cm}^{-2}$. The plane uniformity of the Pt loading in the carbon paper was measured at the $3 \times 3$ point on the loaded area by XRF (XRF membrane thickness meter, FT110A, Hitachi High-Tech Science Corp.). The X-ray tube current, voltage, and collimator diameter were $50 \mathrm{kV}, 1 \mathrm{~mA}$, and $\Phi 0.2 \mathrm{~mm}$, respectively. The variation in the values was within $10 \%$. The fabricated cathode was hot-pressed on the PEM at $4 \mathrm{MPa}$ for $3 \mathrm{~min}$, and the press temperature for the NRE212 and E87-05s was 120 and $145^{\circ} \mathrm{C}$, respectively, due to the difference in the glass transition temperature.

In the anode and cathode chambers of the electrolyzer flowed $1 \mathrm{M} \mathrm{H}_{2} \mathrm{SO}_{4}$ and toluene at 10 and 5 $\mathrm{mL} \mathrm{min}^{-1}$, respectively. The toluene concentrations were 100 and $10 \%$ on dilution with methylcyclohexane. The cell was operated at 60 and $80{ }^{\circ} \mathrm{C}$. The electrochemical measurements involved linear sweep voltammetry (LSV, 1.3-2.0 V, scan rate; $4 \mathrm{mV} \mathrm{s}^{-1}$ ), chronoamperometry (CA, 1.3-2.0 V, time per a constant voltage; $3 \mathrm{~min}$ ), electrochemical impedance spectroscopy (EIS, frequency; $100 \mathrm{k}-0.1 \mathrm{~Hz}$, amplitude; $10 \mathrm{mV}$ ), and current efficiency measurements. The intercept of the real axis for the plots on the high frequency side in the EIS indicated the internal resistance 
including the PEM and the contact resistance in the electrolyzer. The internal resistance was measured at 1.3-2.0 V. The current efficiency was measured by the following method: the volume ratio of the toluene-methylcyclohexane solution and the generated hydrogen gas, which was obtained at the outlet of the cathode chamber, was measured at a constant voltage from 1.0 to $2.0 \mathrm{~V}$. The current efficiency was calculated by Faraday's law.

\section{Results and Discussion}

\subsection{Toluene permeation test for the SPE membrane}

The toluene permeability was evaluated by observing the change in the permeated tolueneconcentration with time. Fick's first law, which was applied for the membrane, is defined by the following equation (1).

$$
J=D \frac{c_{\mathrm{TL}}-c(t)}{d}
$$

where $J, D, c_{\mathrm{TL}}, c(t)$, and $d$ are the flux of toluene in the membrane from the toluene side to the sulfuric acid side, the diffusion coefficient of toluene, the solubility of toluene in the membrane, the permeated toluene concentration in the membrane as a function of time, and the thickness of the membrane, respectively. The membrane separation is strongly influenced by the partition of the solute between the membrane and the adjacent solution. Here, $H$ is defined as the distribution coefficient of the toluene concentration at the sulfuric acid-PEM interface. $c_{\mathrm{TL}}$ and $c(t)$ are replaced by the following eq. (2) and eq. (3), respectively.

$$
\begin{aligned}
& c_{T L}=H C_{T L} \\
& c(t)=H C(t)
\end{aligned}
$$

where $C_{\mathrm{TL}}$ and $C(t)$ are the solubility of toluene in the sulfuric acid and the permeated toluene concentration in the sulfuric acid as a function of time, respectively. The relationship between the concentration change, the flux of toluene in a chamber, and Fick's first law modified by $H$ are expressed by the following eq. (4) and eq. (5), respectively.

$$
\begin{aligned}
& V \frac{\partial C(t)}{\partial t}=J S \\
& J=D H \frac{C_{\mathrm{TL}}-C(t)}{d}
\end{aligned}
$$

where $V, t$, and $S$ are the volume of the sulfuric acid, the time, and the permeation area of the PEM, respectively. The differential equation using Eq. (4) and Eq. (5) yielded the following Eq. (6) for the permeated toluene-concentration as a function of time [23].

$$
C(t)=C_{\mathrm{TL}}\left\{1-\exp \left(\frac{S D H}{V d}\right) t\right\}
$$


The apparent diffusion coefficient of toluene through the PEM is defined as the product of the diffusion coefficient and the distribution coefficient $(=D \times H)$, and adopted as the parameter to depict toluene permeability. $\mathrm{DH}$ can be determined by fitting the measured plot using eq. (6). In this study, the $S, V$, and $d$ are known values based on the experimental setup. Fitting was conducted based on the least squares method.

Figure 3 shows the toluene solubility $C_{\text {sat }}$ in sulfuric acid or water as a function of the temperature [24]. The $C_{\text {sat }}$ in sulfuric acid was less than that in water, though $C_{\text {sat }}$ increased with the temperature in both the sulfuric acid and water. Generally, the solubility of an organic compound has a salting-out effect, which explains the lower solubility of toluene in sulfuric acid than in water. The temperature dependence of toluene solubility in sulfuric acid was lower than that in water. This tendency originates from the difference in the heat of dissolution for toluene in water and sulfuric acid, respectively. If the heat of the endothermic process is high, the dissolution proceeds at a high temperature. Therefore, in this case, the enthalpy for the dissolution of toluene in sulfuric acid was lower than that in water

Figure 4(a) shows the permeated toluene concentration for the PEMs as a function of time in $1 \mathrm{~mol}$ $\mathrm{dm}^{-1}$ of sulfuric acid at $60^{\circ} \mathrm{C}$. In this figure, each line was fitted using eq. (3). The permeated toluene concentration of N117 was much lower than that of the others, because the flux of the permeated toluene through the membrane is inversely proportional to the membrane thickness as expressed in eq. (2). The thickness of N117 is greater than three times that of the other PEMs as shown in Table 1. Figure 4(b) shows the Arrhenius plots of the apparent diffusion coefficients for the PEMs. The apparent diffusion coefficients were determined using the initial period of the fitted concentration curves in Fig. 4(a). The toluene permeability of all the PEMs increased with increasing temperature following Arrhenius' law. The apparent activation energies, which were calculated from the slope of the Arrhenius plot in Fig. 4(b), are shown in Table 2. These values were in the range of 21-25 kJ mol1 and did not show any significant difference. In a previous report, oxygen was shown to have permeated into the intermediate region of the PEM, which consisted of both hydrophilic and hydrophobic interfaces [25]. Thus, a similar situation would arise in the case of toluene permeation in the PEM as it also involves the permeation of low solubility molecules in the hydrophilic phase. If the path of the toluene permeation is also in the intermediate region, the effect of the functional group or Teflon main chain on the PEMs might be low, and there will be a slight difference in the apparent activation energies with the various PEMs. The activation energies for the membrane permeation of water and methanol, which were obtained from the diffusion coefficient, were 12 and $18 \mathrm{~kJ} \mathrm{~mol}^{-1}$, respectively [26, 27]. The apparent activation energy of $23 \mathrm{~kJ} \mathrm{~mol}^{-1}$ for the membrane permeation of toluene obtained in our study was greater than these values. The diffusion coefficient is described by the Wilke-Chang equation (eq. (4)) [28], 


$$
D=7.4 \times 10^{-8} \frac{\sqrt{x M_{\text {solvent }}} T}{\eta_{\text {solute }}\left(\frac{M_{\text {solute }}}{d_{\text {solute }}}\right)^{0.6}}
$$

where $x, M_{\text {solvent }}, T, \eta_{\text {solute }}, M_{\text {solute }}$, and $d_{\text {solute }}$ are the constant values correlated to the solvent, the molar mass of the solvent, the temperature, the viscosity of the solute, the molar mass of the solute, and the density of the solute, respectively. If the temperature dependences of $\eta_{\text {solute }}$, $M_{\text {solute }}$, and $d_{\text {solute }}$ are negligibly low, the diffusion coefficient of toluene in water has a lower temperature dependence than that of water or methanol because of the lower slope of eq. 4 . It is in contrast to the relationship of the apparent activation energy with the diffusivity of toluene and other solvents $[26,27]$. Therefore, other interactions, such as the affinity of the solute for a solvent (hydrophilicity or hydrophobicity) and hydrogen bonding, might affect the temperature dependence of the permeation.

The apparent diffusion coefficients of toluene in Aquivion ${ }^{\circledR}$ were lower than that in Nafion ${ }^{\circledR}$. The water uptake of the PEMs increases with the decrease in the $E W$ and the increase in the side chain length, because the increase in the hydrophilic functional group concentration or the flexibility causes retention of the absorbed water. Therefore, the SSC structure would have a relatively lower water uptake than the LSC structure. A. Ghielmi et al. reported that the water uptakes of the N117, the E8705S, and the E98-05S are 35, 42, and $34 \%$, respectively [29]. The PEM with a low water uptake means a small cross section of the hydrophilic phase, which would be proportional to the hydrophilic and hydrophobic interfaces as the permeation path of the toluene. Furthermore, the PEM with a low $E W$ has a low toluene solubility in the hydrophilic region, because the high concentration of the sulfonic acid group would suppress the toluene solubility due to the salting-out effect. The N117 and the E98-05S have similar water uptakes, though the $E W$ of E98-05S is lower than that of N117. Therefore, the toluene permeation region might also be similar, though the solubility of toluene in the permeation region of E98-05S is higher than that of N117. This could be a reason for the lower apparent diffusion coefficient of E98-05S than that of N117. Also, E87-05S has a higher water uptake and lower $E W$ than E98-05S. Therefore, the toluene permeation region of E87-05S would be greater than that of E98-05S, and the solubility of toluene in the permeation region of E87-05S would be lesser than that of E98-05S. As a result, the apparent diffusion coefficients of E87-05S and E98-05S were almost the same by the trade-off relationship.

3.2 Electrochemical measurement in the toluene direct electro-hydrogenation electrolyzer using the SPE membrane and ionomer

Figure 5 shows the LSV curves and the current density dependence of the internal resistances for the different combinations of the membrane and ionomer at 60 and $80^{\circ} \mathrm{C}$ in the toluene direct electro- 
hydrogenation electrolyzer. The membrane/ionomer combinations comprised of the following four types: NRE212/Nafion, NRE212/Aquivion, E87-05s/Nafion, and E87-05s/Aquivion. The samples using NRE212 as the membrane showed a lower cell voltage than those using the E87-05s. With an increase in the temperature from 60 to $80^{\circ} \mathrm{C}$, the cell voltage and the internal resistance decreased ca. $0.12 \mathrm{~V}$ at $400 \mathrm{~mA} \mathrm{~cm}^{-2}$ and $0.08 \Omega \mathrm{cm}^{-2}$ in all the current density regions for both membrane cells. The order of the internal resistance approximately corresponded to the cell voltage for all the membrane and ionomer combinations at the various temperatures. However, it cannot quantitatively explain that the difference in the cell voltage originated only from the $I R$ loss by the internal resistance. The other factor affecting the cell voltage is mentioned in the following result.

Figure 6 shows the comparison of the anode and cathode polarization curves at 60 and $80{ }^{\circ} \mathrm{C}$ with $10 \% \mathrm{TL}$ and for 100 and $10 \%$ toluene at $60^{\circ} \mathrm{C}$ for the combinations of the membrane and ionomer in the toluene direct electro-hydrogenation electrolyzers. Each polarization curve was obtained by chronoamperometry. For the toluene direct electro-hydrogenation, the standard electrode potentials of cathode and anode are 0.15 and $1.23 \mathrm{~V}$ vs. RHE, respectively [11]. In Figs. 6(a)-(i) and (a)-(ii), the overpotential decreased with the increasing temperature in both the anode and cathode for all the samples. On the other hand, the anode polarization curves were not affected by the change in toluene concentration and the combination of the membrane and ionomer, as shown in Figs. 6(a)-(i) and (b)(i). In Fig 6 (b)-(ii), the cathode overpotential for all the combinations increased with decreasing toluene concentration. This result would originate from the mass transfer effect of toluene. The order of the cathode overpotential in Figs. 6 (a)-(ii) and (b)-(ii) was NRE212/Nafion $<$ NRE212/Aquivion< E87-05s/Nafion $<$ E87-05s/Aquivion at each temperature. Nafion ${ }^{\circledR}$ has the advantage of a low overpotential in both the membrane and ionomer. Furthermore, the result NRE212/Aquivion $<$ E87$05 \mathrm{~s} / \mathrm{Nafion}$ based on the polarization curves might show that the mass transfer enhancement property of the high $E W$ membrane has a stronger effect on the overpotential than that of the high $E W$ ionomer.

Figure 7 shows the current efficiency as a function of the current density for all the combinations of membranes and ionomers with a $10 \%$ toluene feed. For practical use of this electrolyzer, the electrode size would be $1 \mathrm{~m}^{2}$. The ideal performance of the electrolyzer is a $100 \%$ rate of conversion from toluene to methylcyclohexane by a one-pass operation. In such a case, the electrode area in the vicinity of the outlet should have a low toluene concentration. In this study, the inlet of $10 \%$ toluene for the electrolyzer demonstrated ideal performance. In our previous study, we reported that the toluene direct electro-hydrogenation using the electrolyzer showed no detectable by-products such as methylcyclohexadienes or methylcyclohexenes $[19,20]$. Therefore, the decrease in current efficiency is equivalent to an increase in hydrogen generation. For all the combinations of the membrane and ionomer and all regions of the current density, NRE212/Nafion and E87-05s/Aquivion showed the highest and lowest current efficiency performances, respectively. For the different combinations of the membrane and ionomer, NRE212/Aquivion showed a higher performance in the low current density 
region than E87-05s/Aquivion, while the reverse occurred in the high current density region over 300 $\mathrm{mA} \mathrm{cm}{ }^{-2}$. The current density at the beginning of the current-efficiency drop depended on the membrane type, and these values for E87-05s and NRE212 were ca. 100 and $200 \mathrm{~mA} \mathrm{~cm}^{-2}$, respectively. At low current density, the toluene hydrogenation reaction in the cathode catalyst layer mainly occurred in the vicinity of the interface between the membrane and the cathode catalyst layer as shown in Fig. 8 (a) (cf. Fig. S1). In such a situation, the SPE around the active cathode catalyst is almost at the surface of the membrane, and the current efficiency performance is affected by the membrane property. The toluene hydrogenation reaction occurs at the three-phase boundary (TPB) of toluene, the electron and the proton on the cathode catalyst surface [21]. In this case, toluene is supplied through the ionomer or directly to the TPB. The shortage of the toluene supply to the TPB causes hydrogen generation and decreases the current efficiency. In Fig. 7, the current density at the beginning of the current efficiency drop for NRE212 showed a higher value than that for E87-05s. The possible reason for this is that NRE212 had a higher toluene permeability than E87-05s as shown in Fig. 4. For this property, the shortage of toluene on the TPB in the surface of NRE212 was more suppressed than that of E87-05s. In a short term of about ten hours, NRE212 was superior to E87-05s as the membrane. However, on the industrial time scale, in which the electrolyzer operates for several tens of thousands of hours, the toluene permeation to the anode side through the membrane causes a decrease in the anode activity by poisoning of the catalyst [14]. Hence, it is not necessary that the SPE membrane with a higher toluene permeability is better from a comprehensive standpoint. Further optimization of the membrane design would be required.

In the high current density region over $300 \mathrm{~mA} \mathrm{~cm}^{-2}$, the slope of the current efficiency curves is affected by the ionomer type, and the slope for $\mathrm{Nafion}^{\circledR}$ was lower than that of Aquivion ${ }^{\circledR}$. This tendency means that Nafion ${ }^{\circledR}$ better suppressed the hydrogen generation than Aquivion ${ }^{\circledR}$. At the high current density, the reaction area of the toluene hydrogenation would be the entire cathode catalyst layer as shown in Fig. 8 (b). For this situation, the ionomer would significantly dominate the toluene supply to the TPB than the membrane surface. In other words, at high current density, the different ionomer types mainly affect the electrochemical performance rather than that of the membrane type. Consequently, the higher performance of $\mathrm{Nafion}^{\circledR}$ in Fig. 7 originates from the higher toluene permeability than that of Aquivion ${ }^{\circledR}$. This result would simply conclude that $\mathrm{Nafion}^{\circledR}$ was superior to Aquivion $^{\circledR}$ as the ionomer, which is different to that in the case of membranes.

\section{Conclusions}

In this study, we clarified the mechanism for toluene permeability in solid polymer electrolytes and the relationship between the electrochemical performance and the properties of the PEM and the ionomer, which contained the EW and molecular structure. For improving the performance of the 
toluene direct electro-hydrogenation system, the toluene permeability through the PEMs with various equivalent weights $(E W)$ and lengths of the side chain was quantitatively investigated using a the twochamber cell. The apparent activation energy, which was obtained from the Arrhenius plot, was about $23 \mathrm{~kJ} \mathrm{~mol}^{-1}$ for all the PEMs. This value was lower than those for methanol $\left(18 \mathrm{~kJ} \mathrm{~mol}^{-1}\right)$ and water $\left(12 \mathrm{~kJ} \mathrm{~mol}^{-1}\right)$ in the PEM, and contrary to the Wilke-Chang equation. This would be affected by the affinity of the solute for the solvent. The PEM with the SSC structure and low $E W$ would suppress the toluene permeation, because a PEM with a low water uptake leads to a small interfacial region as the toluene permeation path due to the small cross section of the hydrophilic area. The PEM with a low $E W$ caused a low toluene solubility because of the salting-out effect due to the high concentration of the ion-exchange group.

The electrochemical test using the SPE membrane and ionomer was performed using the toluene direct electro-hydrogenation electrolyzer. The electrolyzer, which used the SPE with the LSC structure and high $E W$ for both the membrane and ionomer, showed the highest performance. This result originates from the higher toluene permeability due to the high toluene-transport property to the TPB. Consequently, the ionomer was superior to the SPE with the higher toluene permeability. For the membrane, the SPE with the high toluene permeability had the advantage in short-term electrochemical performances. However, the SPE with the low toluene permeability is better for longtime operations in practice. Hence, the SPE membrane for the toluene direct electro-hydrogenation electrolyzer would need to be optimized and designed to control the toluene permeation.

\section{Acknowledgements}

This study was supported by the Council for Science, Technology and Innovation (CSTI), Crossministerial Strategic Innovation Promotion Program (SIP): “energy carrier” (Funding agency: JST), Toyota Mobility Foundation, and Core Research for Evolutional Science and Technology (CREST): “innovative reaction" (Funding agency: JST).

\section{References}

[1] R. B. Biniwale, S. Rayalu, S. Devotta, M. Ichikawa, Chemical hydrides: A solution to high capacity hydrogen storage and supply, Int. J. Hydrogen Energy. 33 (2008) 360-365.

[2] J. Chupin, N. S. Gnep, S. Lacombe, M. Guisnet, Influence of the metal and of the support on the activity and stability of bifunctional catalysts for toluene hydrogenation, Appl. Catal. A 206 (2001) 43-56.

[3] U. Schmiemann, H. Baltruschat, J. The influence of the single-crystal orientation on the electrocatalytic hydrogenation of benzene and the H-D exchange, Electroanal. Chem. 347 (1993) 93-109.

[4] A. T. Wijayanta, T. Oda, C. W. Purnomo, T. Kashiwagi, M. Aziz, Liquid hydrogen, 
methylcyclohexane, and ammonia as potential hydrogen storage: Comparison review, Int. J. Hydrogen Energy. 44 (2019) 15026-15044.

[5] Y. Okada, E. Sasaki, E. Watanabe, S. Hyodo, H. Nishijima, Development of dehydrogenation catalyst for hydrogen generation in organic chemical hydride method, Int. J. Hydrogen Energy. 31 (2006) 1348-1356.

[6] P. Wang, T. Minegishi, G. Ma, K. Takanabe, Y. Satou, S. Maekawa, Y. Kobori, J. Kubota, K. Domen, Photoelectrochemical conversion of toluene to methylcyclohexane as an organic hydride by $\mathrm{Cu} 2 \mathrm{ZnSnS}$ 4-based photoelectrode assemblies, J. Am. Chem. Soc. 134 (2012) 2469-2472.

[7] M. V. Rahaman, M. A. Vannice, The hydrogenation of toluene and o-, m-, and pxylene over palladium: I. Kinetic behavior and o-xylene isornerization, J. Catal. 127 (1991) 251-266.

[8] S. D. Lin, C. Song, Noble metal catalysts for low-temperature naphthalene hydrogenation in the presence of benzothiophene, Catal. Today. 31 (1996) 93-104.

[9] E. Newson, Th. Haueter, P. Hottinger, F. Von Roth, G. W. H. Scherer, Th. H. Schucan, Seasonal storage of hydrogen in stationary systems with liquid organic hydrides, Int. J. Hydrogen Energy. 23 (1998) 905-909.

[10] M. Niermann, A. Beckendorff, M. Kaltschmitt, K. Bonhoff, Liquid organic hydrogen carrier (LOHC) - Assessment based on chemical and economic properties, Int. J. Hydrogen Energy. 44, (2019) 6631-6654.

[11] S. Mitsushima, Y. Takakuwa, K. Nagasawa, Y. Sawaguchi, Y. Kohno, K. Matsuzawa, Z. Awaludin, A. Kato, Y. Nishiki, Membrane electrolysis of toluene hydrogenation with water decomposition for energy carrier synthesis, Electrocatalysis. 2 (2015) 127-131.

[12] K. Nagasawa, Y. Sawaguchi, A. Kato, Y. Nishiki, S. Mitsushima, Rate-determining factor of the performance for toluene electrohydrogenation electrolyzer, Electrocatalysis. 8 (2017) 164-169.

[13] M. Wakisaka, M. Kunitake, Direct electrochemical hydrogenation of toluene at Pt electrodes in a microemulsion electrolyte solution, Electrochem. Commun. 64 (2016) 5-8.

[14] K. Nagai, K. Nagasawa, S. Mitsushima, OER activity of Ir-Ta-Zr composite anode as a counter electrode for electrohydrogenation of toluene, Electrocatalysis. 7 (2016) 441-444.

[15] A. S. Aricò, A. Di Blasi, G. Brunaccini, F. Sergi, G. Dispenza, L. Andaloro, M. Ferraro, V. Antonucci, P. Asher, S. Buche, D. Fongalland, G.A. Hards, J.D.B. Sharman, A. Bayer, G. Heinz, N. Zandonà, R. Zuber, M. Gebert, M. Corasaniti, A. Ghielmi, D. J. Jones, High temperature operation of a solid polymer electrolyte fuel cell stack based on a new ionomer membrane, Fuel Cells. 10 (2010) 1013-1023.

[16] R. B. Moore, C.R. Martin, Morphology and chemical properties of the Dow perfluorosulfonate ionomers, Macromolecules. 22 (1989) 3594-3599.

[17] A. Stassi, I. Gatto, E. Passalacqua, V. Antonucci, A.S. Arico, L. Merlo, C. Oldani, E. Pagano, Performance comparison of long and short-side chain perfluorosulfonic membranes for high 
temperature polymer electrolyte membrane fuel cell operation, J. Power Sources. 196 (2011) 8925-8930.

[18] S. Siracusano, V. Baglio, A. Stassi, L. Merlo, E. Moukheiber, A.S. Arico', Performance analysis of short-side-chain Aquivion ${ }^{\circledR}$ perfluorosulfonic acid polymer for proton exchange membrane water electrolysis, J. Memb. Sci. 466 (2014) 1-7.

[19] K. Takano, H. Tateno, Y. Matsumura, A. Fukazawa, T. Kashiwagi, K. Nakabayashi, K. Nagasawa, S. Mitsushima, M. Atobe, Electrocatalytic hydrogenation of toluene using a proton exchange membrane reactor, Bull. Chem. Soc. Jpn. 89 (2016) 1178-1183.

[20] K. Takano, H. Tateno, Y. Matsumura, A. Fukazawa, T. Kashiwagi, K. Nakabayashi, K. Nagasawa, S. Mitsushima, M. Atobe, Electrocatalytic hydrogenation of $o$-Xylene in a PEM Reactor as a Study of a Model Reaction for Hydrogen Storage, Chem. Lett. 45 (2016) 1437-1439.

[21] K. Nagasawa, A. Kato, Y. Nishiki, Y. Matsumura, M. Atobe, S. Mitsushima, The effect of flowfield structure in toluene hydrogenation electrolyzer for energy carrier synthesis system, Electrochim. Acta 246 (2017) 459-465.

[22] K. Nagasawa, Y. Sawaguchi, A. Kato, Y. Nishiki, S. Mitsushima, Chemical-hydrogenation functionalized flow-field in toluene direct electro-hydrogenation electrolyzer for energy-carrier synthesis system, Electrochemistry 86 (2018) 339-344.

[23] E. L. Cussler, "Diffusion - Mass Transfer in Fluid Systems", p.428, Cambridge University Press (1997).

[24] “3rd ed. Kagaku Binran Kisohen", p.II-204, The Chemical Society of Japan ed., Maruzen Publishing Co., Ltd. (1984).

[25] Z. Ogumi, T. Kuroe, Z. Takehara, Gas permeation in SPE method II. Oxygen and hydrogen permeation through Nafion, J. Electrochem. Soc. 132 (1985) 2601-2605.

[26] T. Okada, G. Xie, M. Meeg, Simulation for water management in membranes for polymer electrolyte fuel cells, Electrochim. Acta 43 (1998) 2141-2155.

[27] V. Tricoli, N. Carretta, M. Bartolozzi, A comparative investigation of proton and methanol transport in fluorinated ionomeric membranes, J. Electrochem. Soc. 147 (2000) 1286.

[28] Wilke, C. R., and Pin Chang, Correlation of diffusion coefficients in dilute solutions, A. I. Ch. E. J. 1 (1955) 264-270.

[29] A. Ghielmi, P. Vaccarono, C. Troglia, V. Arcella, Proton exchange membranes based on the shortside-chain perfluorinated ionomer, J. Power Sources. 145 (2005) 108-115. 
Figure and Table captions

Table 1 Thickness, $E W$ and polymer structure of N117, NRE212, E87-05S and E98-05S.

Table 2 The apparent activation energy of toluene permeability with N117, NRE212, E87-05S, and E98-05S determined by the results of the permeation test.

Fig. 1 The polymer structures of (a) Nafion ${ }^{\circledR}$ and (b) Aquivion ${ }^{\circledR}$.

Fig. 2 Schematic structure and conditions of (a) toluene permeation test, (b) toluene solubility measurement in $1 \mathrm{~mol} \mathrm{dm}^{-3}$ sulfuric acid and (c) toluene direct electro-hydrogenation electrolyzer.

Fig. 3 The toluene solubility in $1 \mathrm{~mol} \mathrm{dm}^{-3}$ sulfuric acid solution (measured) or water [18] as a function of temperature.

Fig. 4 The (a) permeated toluene concentration as a function of time in the $1 \mathrm{~mol} \mathrm{dm}^{-3}$ of sulfuric acid solution at $60^{\circ} \mathrm{C}$ and the (b) Arrhenius plots of the apparent diffusion coefficients with N117, NRE212, E87-05S, and E98-05S membranes.

Fig. 5 The (a) LSV curves and the (b) current density dependence of internal resistance for the different combinations of the membrane and ionomer at 60 and $80{ }^{\circ} \mathrm{C}$ in the toluene direct electrohydrogenation electrolyzer.

Fig. 6 Comparison of the (i) anode and (ii) cathode polarization curves at (a) 60 and $80{ }^{\circ} \mathrm{C}$ with $10 \%$ $\mathrm{TL}$ and for (b) 100 and $10 \%$ toluene at $60{ }^{\circ} \mathrm{C}$ for the combinations of membrane and ionomer in the toluene direct electro-hydrogenation electrolyzers.

Fig. 7 The current efficiency for all the combinations of membranes and ionomers with $10 \%$ toluene.

Fig. 8 Schematic drawing of the reaction area at the (a) low and (b) high current density in the cathode catalyst layer. 
(a) LSC (Long Side Chain) type

$-\left(\mathrm{CF}_{2} \mathrm{CF}_{2}\right)_{n} \mathrm{CF}_{2} \mathrm{CF}-$

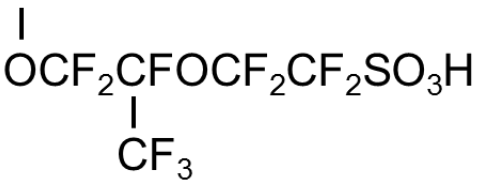

(b) SSC (Short Side Chain) type

$-\left(\mathrm{CF}_{2} \mathrm{CF}_{2}\right)_{n} \mathrm{CF}_{2} \mathrm{CF}-$

I

$\mathrm{OCF}_{2} \mathrm{CF}_{2} \mathrm{SO}_{3} \mathrm{H}$

Fig. 1 The polymer structures of (a) Nafion ${ }^{\circledR}$ and (b) Aquivion ${ }^{\circledR}$. 
(a)

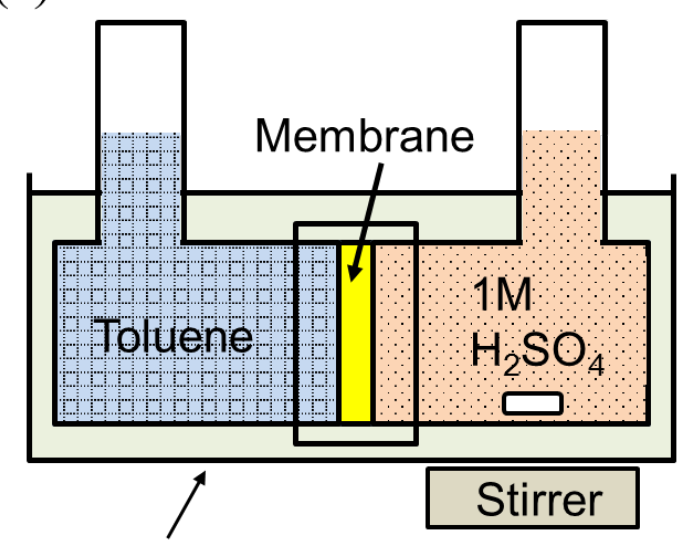

Water bath (b)

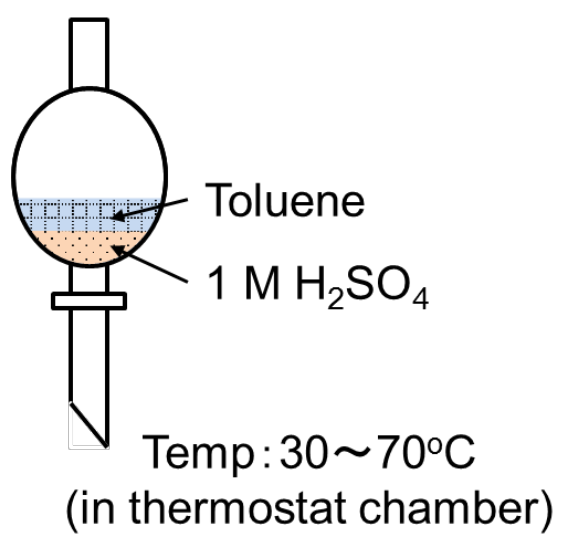

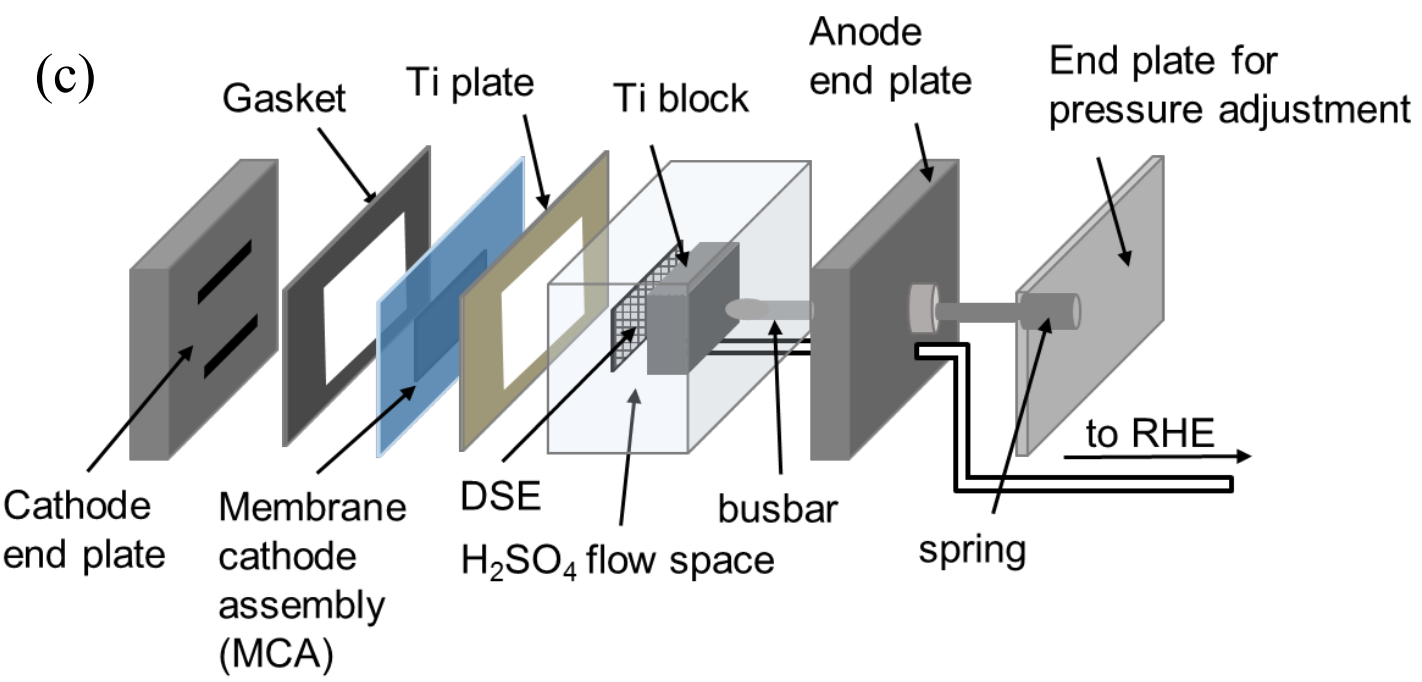

Fig. 2 Schematic structure and conditions of (a) toluene permeation test, (b) toluene solubility measurement in $1 \mathrm{~mol} \mathrm{dm}^{-3}$ sulfuric acid and (c) toluene direct electro-hydrogenation electrolyzer. 


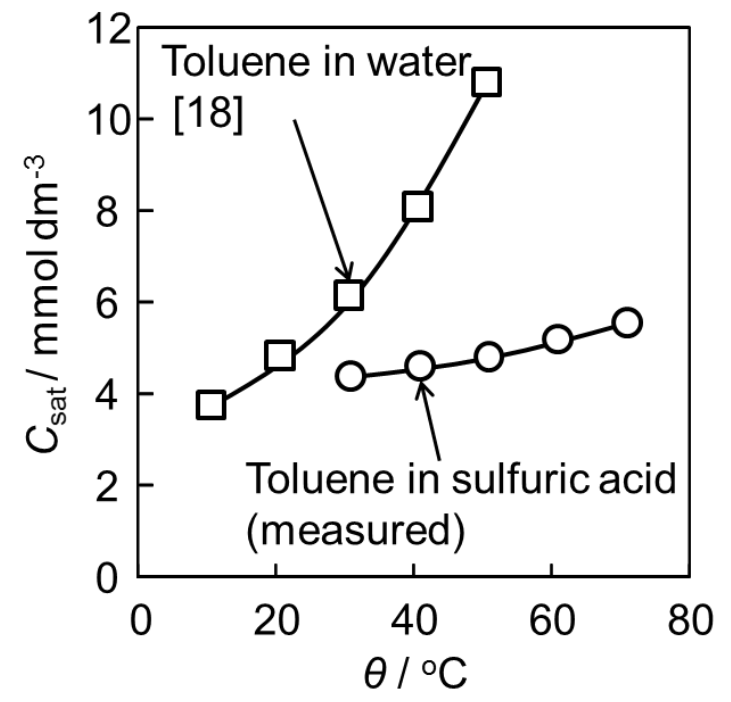

Fig. 3 The toluene solubility in $1 \mathrm{~mol} \mathrm{dm}^{-3}$ sulfuric acid solution (measured) or water [18] as a function of temperature. 

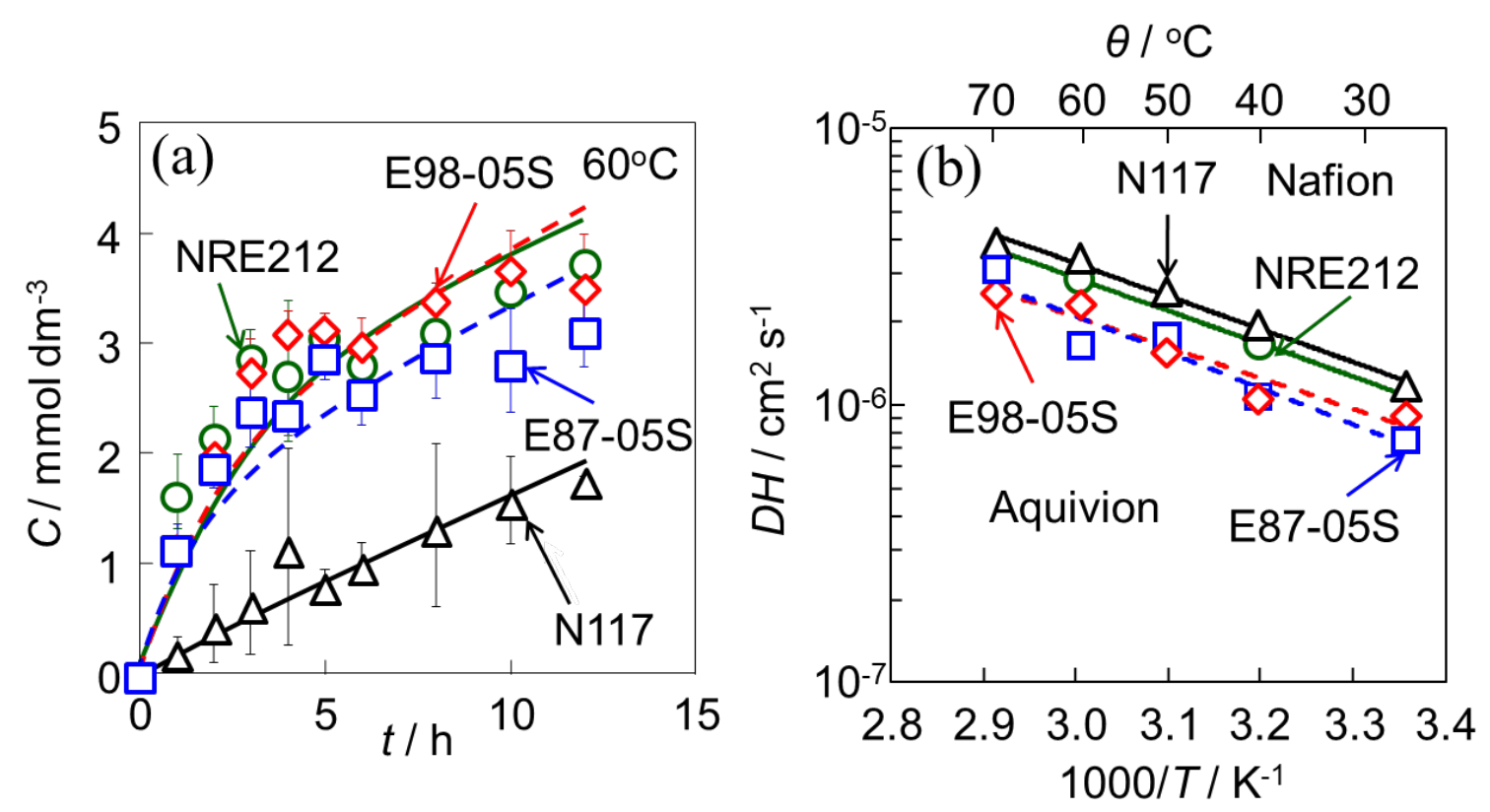

Fig. 4 The (a) permeated toluene concentration as a function of time in the $1 \mathrm{~mol} \mathrm{dm}^{-3}$ of sulfuric acid solution at $60^{\circ} \mathrm{C}$ and the (b) Arrhenius plots of the apparent diffusion coefficients with N117, NRE212, E87-05S, and E98-05S membranes. 


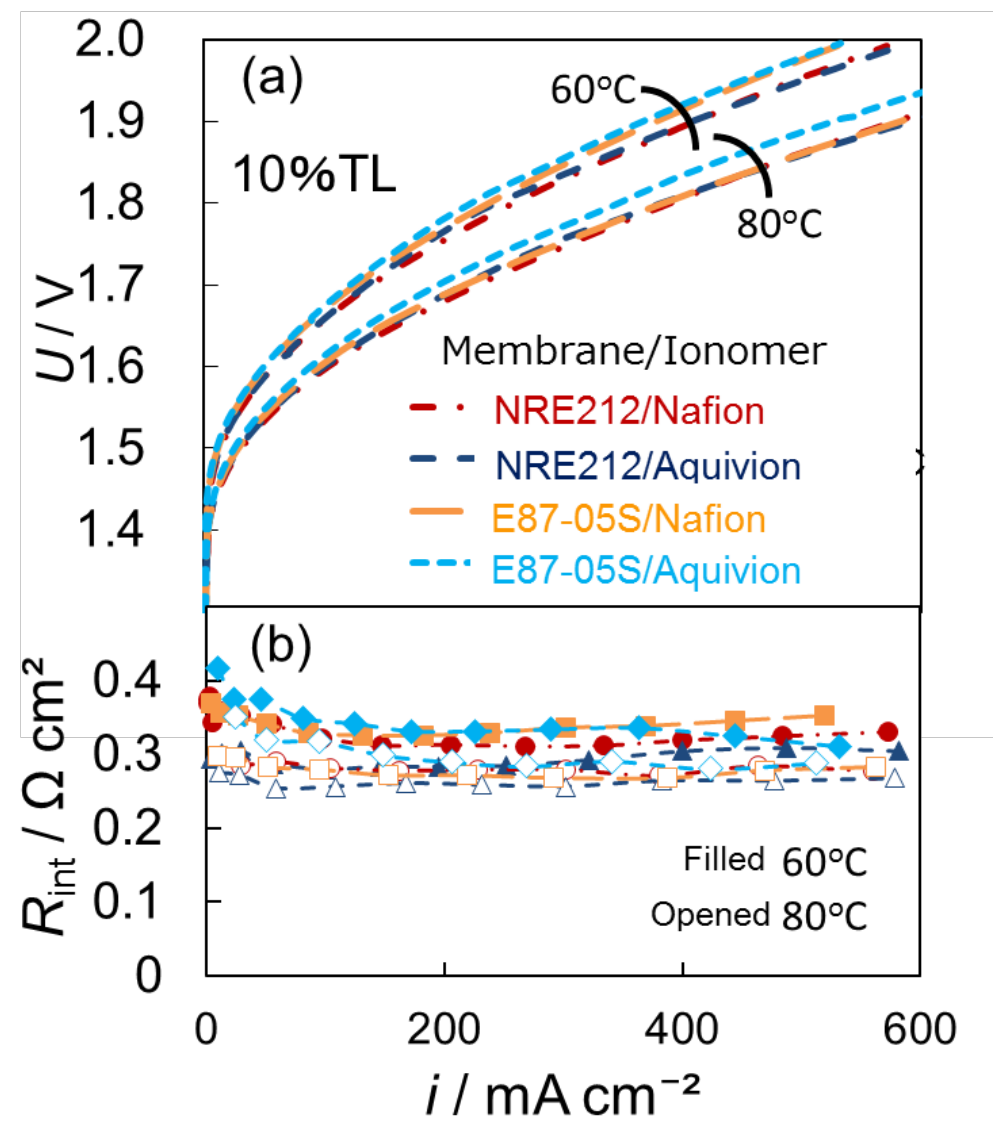

Fig. 5 The (a) LSV curves and the (b) current density dependence of internal resistance for the different combinations of the membrane and ionomer at 60 and $80{ }^{\circ} \mathrm{C}$ in the toluene direct electrohydrogenation electrolyzer. 

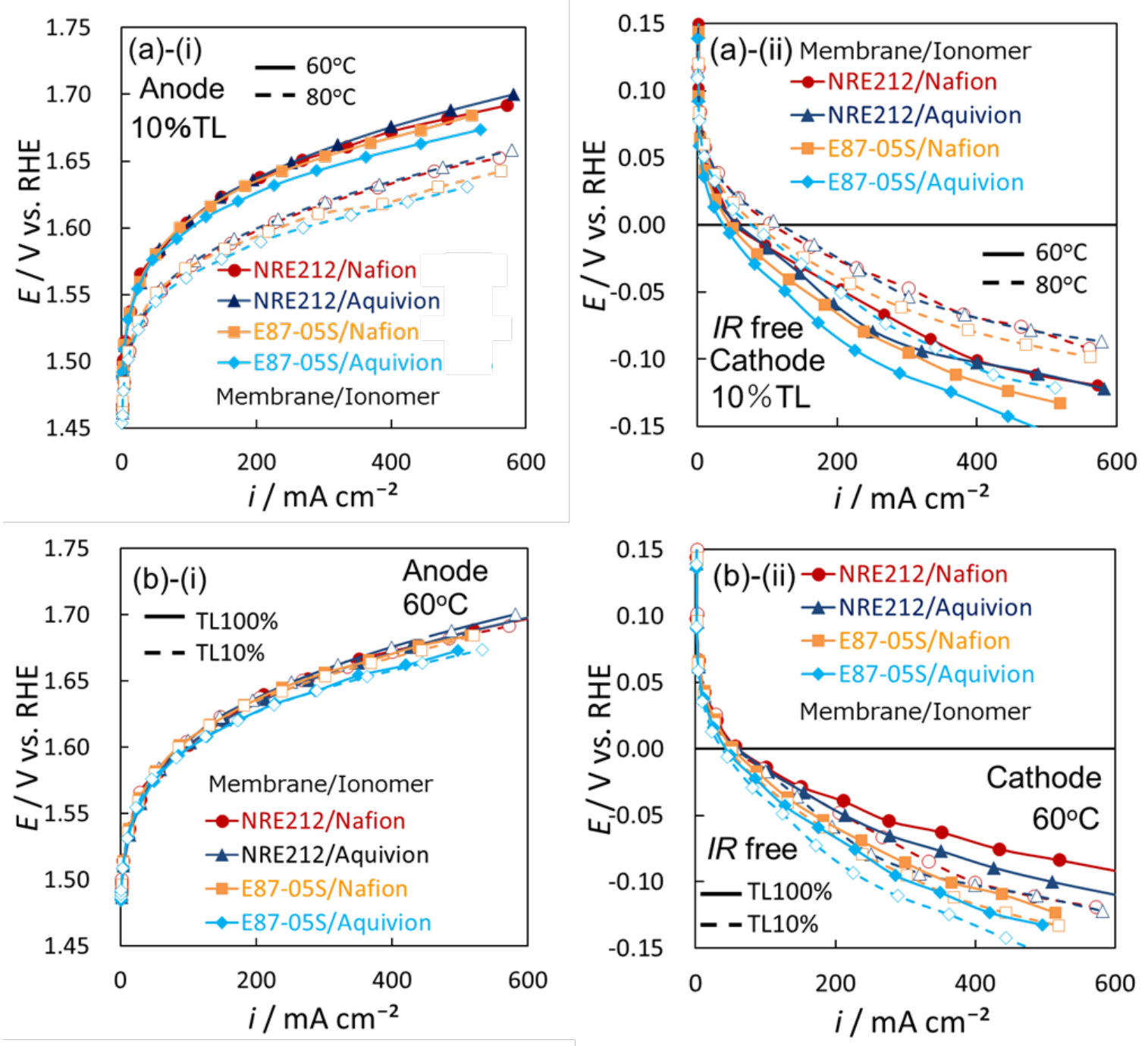

Fig. 6 Comparison of the (i) anode and (ii) cathode polarization curves at (a) 60 and $80{ }^{\circ} \mathrm{C}$ with $10 \%$ $\mathrm{TL}$ and for (b) 100 and $10 \%$ toluene at $60^{\circ} \mathrm{C}$ for the combinations of membrane and ionomer in the toluene direct electro-hydrogenation electrolyzers. 


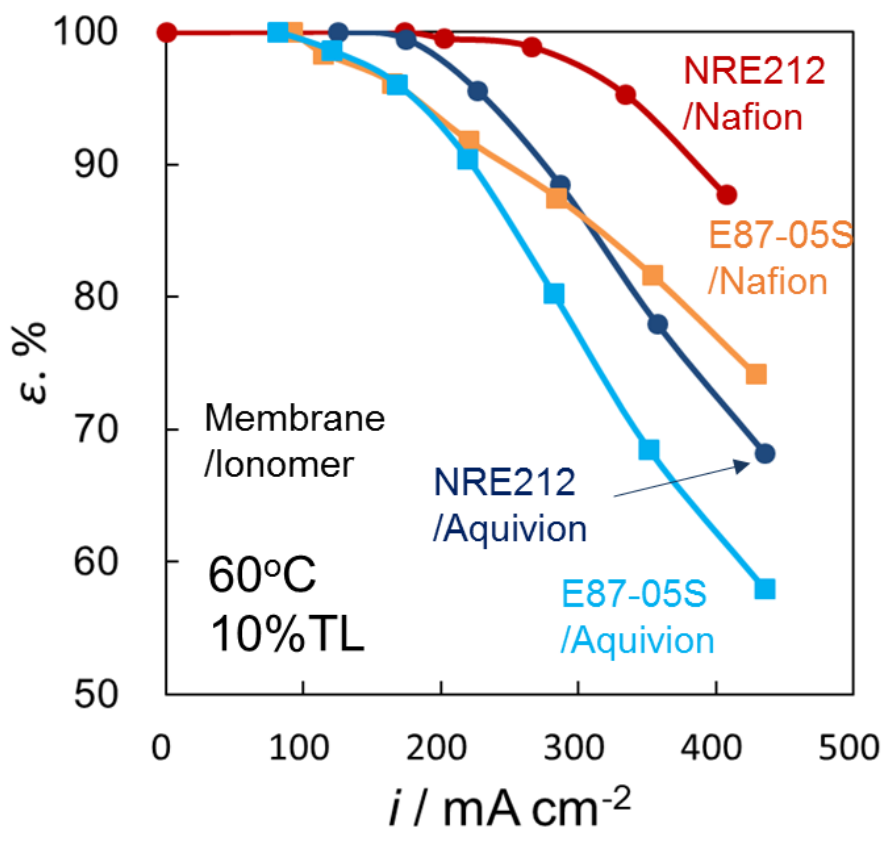

Fig. 7 The current efficiency for all the combinations of membranes and ionomers with $10 \%$ toluene. 

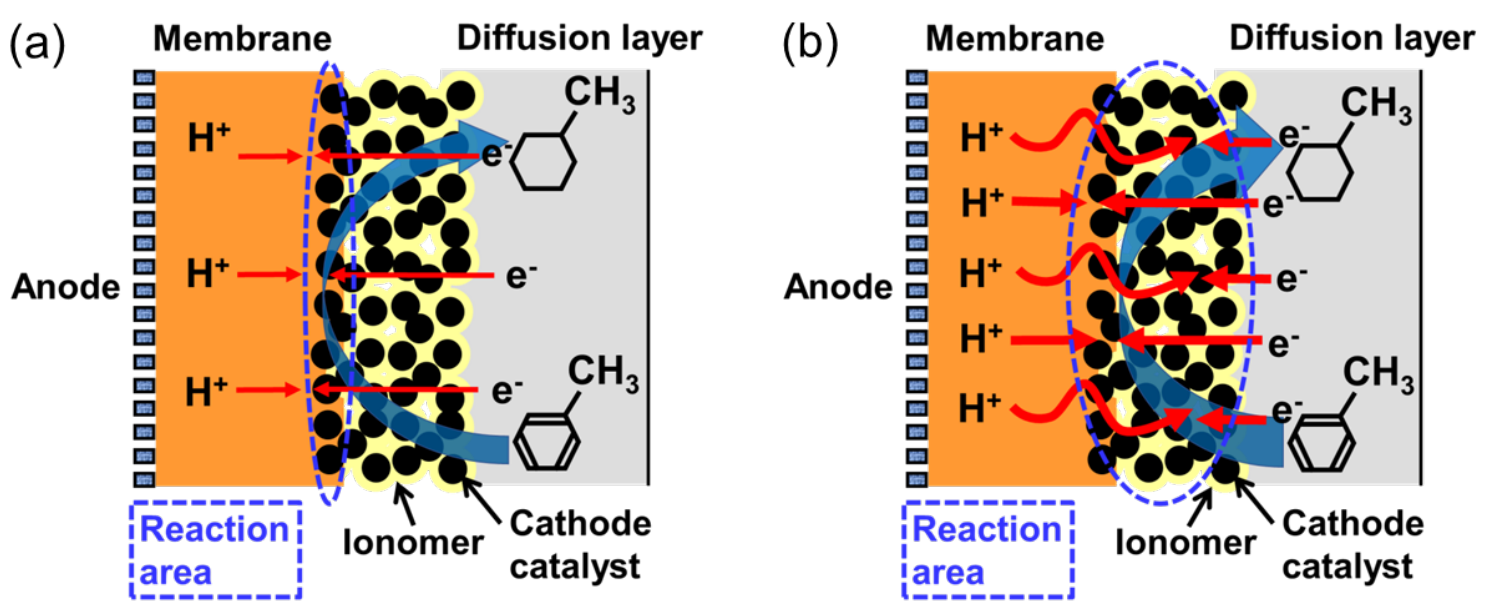

Fig. 8 Schematic drawing of the reaction area at the (a) low and (b) high current density in the cathode catalyst layer. 
Table 1 Thickness, EW and polymer structure of N117, NRE212, E87-05S and E98-05S.

\begin{tabular}{c|ccc}
\hline Membrane & $\begin{array}{c}\text { Thickness } \\
d / \mu \mathrm{m}\end{array}$ & $E W / \mathrm{g} \mathrm{eq}^{-1}$ & $\begin{array}{c}\text { Polymer } \\
\text { structure }\end{array}$ \\
\hline N117 & 183 & 1100 & LSC \\
NRE212 & 51 & 1100 & LSC \\
E87-05S & 53 & 870 & SSC \\
E98-05S & 54 & 980 & SSC \\
\hline
\end{tabular}

Table 2 The apparent activation energy of toluene permeability with N117, NRE212, E87-05S, and E98-05S determined by the results of the permeation test.

\begin{tabular}{c|c}
\hline Membrane & $E_{\mathrm{a}} / \mathrm{kJ} \mathrm{mol}^{-1}$ \\
\hline N117 & $23 \pm 2$ \\
NRE212 & $23 \pm 2$ \\
E87-05S & $25 \pm 3$ \\
E98-05S & $21 \pm 2$ \\
\hline
\end{tabular}

